\title{
The application of Precise Point Positioning in Geosciences
}

\author{
Jakub Kalita ${ }^{a}$,Zofia Rzepecka ${ }^{b}$, Izabela Szuman-Kalita ${ }^{\mathrm{c}}$ \\ ${ }^{a}$ Koszalin University of Technology, Sniadeckich 2, Koszalin 75-453, Poland \\ ${ }^{b}$ University of Warmia and Mazury, Prawochenskiego 15, Olsztyn 10-720, Poland \\ ${ }^{c}$ Adam Mickiewicz University, Dziegielowa 27, Poznan 61-680, Poland
}

\begin{abstract}
Precise Point Positioning (PPP), an absolute positioning method, is an alternative for conventional relative positioning. Currently the PPP accuracy, is on the level of few-centimetres for static and decimetre for kinematic positioning respectively. However, long convergence time of PPP results is observed. The main goal of this paper is to estimate the accuracy and convergence time when using PPP, and to compare the results with those obtained by other authors. The idea, model and expected accuracy of PPP is discussed in first part of the paper. Adding GLONASS, using method of real-time and using only single frequency are analysed in the frame of recent publications. Numerical analysis is based on gLAB, open source desktop software written in C. Analysis was performed for globally distributed set of 25 stations with observation period of 50 consecutive days, enough to produce statistically relevant results. Analysis of convergence time was done for accuracies between $10 \mathrm{~cm}$ and $1 \mathrm{~cm}$. Statistical analysis of accuracy is performed for observation time between $24 \mathrm{~h}$ and $1 \mathrm{~h}$. Both statistical parameters and convergence times for different accuracy reveal exponential nature. Considering observation period of 4 hours, few-centimeter convergence may be expected with no significant biases observed. At current state the method overtakes relative positioning in areas where networks of reference stations are not established. The PPP technique may be attractive not only in geodesy, thus, the application possibility in geosciences is analyzed in context of the results.
\end{abstract}

Keywords: Precise Point Positioning; Geosciences; convergence time; accuracy analysis.

\section{Precise Point Positioning}

\subsection{The idea}

Precise Point Positioning (PPP) is a method of precise absolute positioning based on the Global Navigation Satellite System (GNSS) code and carrier-phase observations. The method was intensively developed by Zumberge et al. [1]. A key element behind this technique is requiring measurements from a single receiver. The receiver's position is obtained on the basis of spatial resection between satellites and the receiver. To obtain the highest quality, one should use a single dual-frequency phase receiver. This contrasts with the conventional relative method where simultaneous measurements at two receivers are required. The difference in observations between both receivers allows one to mitigate various sources of errors. In this case, the vector between receivers is estimated.

Relative methods quality depends on the distance between receivers. In the case of PPP, direct usage of reference stations is no longer needed, and so spatial operating range limit no longer exists, hence the coverage is global. With slightly lower accuracy, labor and equipment costs are reduced while pre-planning and logistics are simplified [2-3]. One of the biggest disadvantages of PPP is the long convergence time.

Precise satellite positions and satellite clock correction are crucial for attaining reasonable accuracy. The international GNSS Service (IGS) has been providing data with several latency and precision levels. The best orbits are obtained as a weighted linear combination from several independent analysis centers [4]. The precision of satellite orbits is 1-2 cm [4-5]. A clock's precision is 20-60 picoseconds. The performance claimed by the IGS is $2.5 \mathrm{~cm}$ and 75 picoseconds for satellite orbits and clocks respectively, while the respective minimal time intervals are 15 minutes and 30 seconds [4].

As an absolute positioning method, PPP should be able to handle relevant factors among which the following can be listed: special and general relativity, Sagnac delay, satellite antenna and clock offsets, phase wind-up, solid earth tides, ocean loading, Earth rotation parameters, and atmospheric pressure loading [6-7]. In the conventional approach, these are

Corresponding author: Jakub Kalita. E-mail address: jakub.kalita@tu.koszalin.pl

http://dx.doi.org/10.3846/enviro.2014.215

(C) 2014 The Authors. Published by VGTU Press. This is an open-access article distributed under the terms of the Creative Commons Attribution License, which permits unrestricted use, distribution, and reproduction in any medium, provided the original author and source are credited. 
mitigated during a double differencing process between the receivers and satellites. Grinter and Roberts [8] compare correction types used by PPP and differential positioning techniques.

\subsection{The model}

Dual frequency measurements allow for the reduction of ionospheric influence since the ionosphere is a dispersive medium with respect to GNSS radio signals. For that purpose, an ionosphere-free linear combination of observations on both frequencies is used. Removing additional effects for the sake of clarity, the observation equation can be defined as in Eqns (1-2) [6].

$$
\begin{gathered}
l_{P}=\rho+C(d t-d T)+\operatorname{Tr}+\varepsilon_{P} \\
l_{\Phi}=\rho+C(d t-d T)+T r+A \lambda+\varepsilon_{\Phi}
\end{gathered}
$$

where:

$l_{P}, l_{\Phi}$ ionosphere-free linear combination of L1 and L2 pseudo-ranges and carrier-phases respectively (m)

$\rho \quad$ geometrical distance between the receiver and the satellite $(\mathrm{m})$

$d t, d T$ station and satellite clock offset respectively from GPS time (s)

$C \quad$ speed of light in a vacuum $(\mathrm{m} / \mathrm{s})$

$\operatorname{Tr} \quad$ signal path delay due to propagation through neutral atmosphere (m)

$A$ ambiguity parameter for the carrier-phase linear combination

$\lambda \quad$ wavelength for carrier-phase linear combination (m)

$\varepsilon_{P}, \varepsilon_{\Phi}$ measurement noise component for pseudo-range and carrier-phase respectively (m)

Basing on Eqns (1-2) the adjustment model can be solved using either sequential least squares adjustment or Kalman filtering [cf. 6-7, 9-10].

\subsection{The accuracy and convergence}

The accuracy of PPP depends on the model. For static positioning, after handling all effects depicted in section 1.1 the method converges to centimeter-level accuracy. This is the accuracy currently claimed by the method [cf. 3-4, 9-13]. Attempts have been made to determine convergence time for accuracy thresholds [cf. 13-15]. Decimeter-level accuracy is reached within first hour of observation decreasing exponentially to single centimeters for 12 and 24 hour periods. The convergence time depends mainly on number and geometry of visible satellites and station specific environment conditions [12]. Recently analysis of number of outliers in function of observation length was analysed [16]. It appears that for lengths greater than 4 hours number of outliers decreases significantly to value of $1 \%$. The analysis considers the influence of precipitation on the accuracy.

Ambiguity fixing plays significant role for kinematic PPP positioning (see Section 1.5). However without it, decimeterlevel accuracy is obtained after several hours of convergence [cf. 12-13, 17]. For both static and kinematic positioning horizontal position is about twice as accurate as vertical.

\subsection{Adding Glonass}

Recently, several analyses of GPS and GLONASS combinations for PPP have been conducted [10, 18-21. For observation periods of $24 \mathrm{~h}$, there is no significant difference between GPS only and GPS/GLONASS solution. In both cases, the positioning accuracy is several millimeters. When sessions of 1-2 hours are taken into consideration, the improvement is significant. For a single station analysed by Stępniak et al. [10], results with errors of up to $2 \mathrm{~cm}$ increased by $20 \%$ after adding GLONASS observations. For sessions lasting 3 hours wherein several GLONASS satellites were visible, an improvement in convergence time and accuracy (correlated to satellite geometry improvement) was observed [18]. Adding the GLONASS system improves satellite geometry by more than $30 \%$. Azab et al. [19] claim that the solution converges to a $3 \mathrm{~cm}$-accuracy after 30 minutes (instead of 3 hours for GPS only), while for time periods longer than 6 hours there is no significant difference. Most study cases carried out by Alcay et al. [20] concur with the above statements. Krzan et al. [21] observe an improvement for short sessions especially when the horizon is limited. To sum up, when taking GLONASS observations into consideration, an increase in the positioning availability and reliability for shorter observation periods is possible. The benefit from adding GLONASS is significant for measuring sites with a limited horizon like canyons, urban areas, and sites near forests or hills. 


\subsection{Fixing ambiguity and real- time PPP}

In taking advantage of precise ephemeris and clock corrections in real-time, obtaining decimeter-level accuracy of real-time PPP becomes possible. After several hours, the accuracy converges to $5 \mathrm{~cm}$ horizontal and $10 \mathrm{~cm}$ vertical [17].

Fixing integer-ambiguities improves convergence time and the final accuracy of positioning using the PPP method. The key is determining satellite and receiver hardware-dependent biases, the so called Un-calibrated Phase Delays [13]. In recent years, successful attempts have been made in this area [22-24]. Two methods for ambiguity resolution based on a network of reference stations have been compared by Geng et al. [24]. The method is inconsistent with the assumption that only a single receiver can be used for positioning; however, the density of reference station networks can be reduced.

After fixing integer-ambiguity, the accuracy improves significantly from decimeter or several centimeters to single centimeters for observation periods of 1 hour. In a study carried out by Geng et al. [24] for hourly data, improvement from 13.7, 7.1 and $11.4 \mathrm{~cm}$ to $0.8,0.9$ and $2.5 \mathrm{~cm}$ for East, North and Up components respectively was observed. However, a convergence time of several tens of minutes for achieving convergence still limits the possibilities for widely applying the technique. For 24-hour sessions, an accuracy of several millimeters horizontally and cm-level can be expected [16, 28], with slight improvement compared to a float ambiguity solution.

\subsection{Single frequency PPP}

A large group of GPS users carry measurements with single frequency receivers, thus the quality of the single frequency solution is worth analyzing [21, 25-27]. The key aspect in that type of processing is mitigation of the ionosphere influence. Such analysis was conducted by Chen and Gao [25]. A strong correlation between the accuracy and ionosphere activity was observed, resulting in an accuracy of single decimeters up to a single meter level for low and high activity, respectively. The quality of the solution depends on the type of receiver. Single decimeters, half a meter, and single-meter accuracy is observed for geodetic quality, GIS-grade, and hand-held low-cost receiver, respectively [26, followed by 28]. In some cases, single frequency PPP can outperform a dual-frequency solution. This situation can be observed for very short observation periods (first 10 minutes) or in areas where the possibility of losing the signal lock is increased [27].

\section{Methodology}

A total of 25 permanent reference stations were used for the analysis (see Fig. 1) of the PPP method's positioning errors. They have been chosen as a subset of the IGS08 core network [29], based on their distribution, quality and continuity of observations.

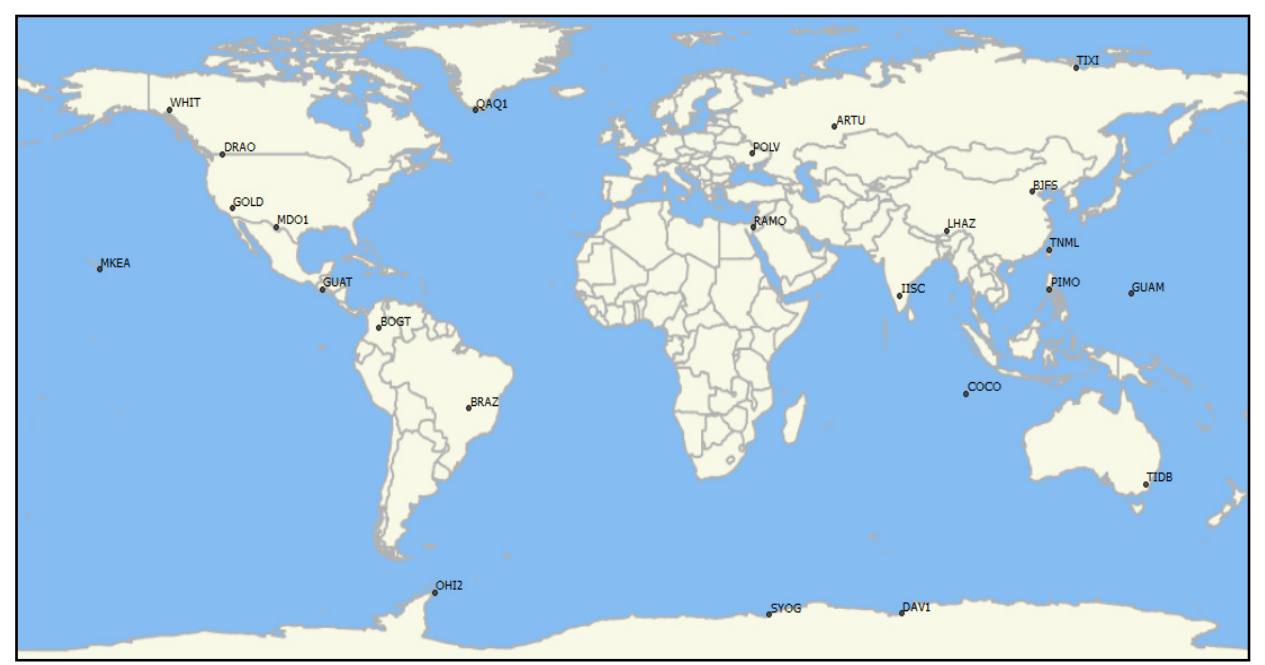

Fig. 1. Permanent stations used for analysis of PPP method

Each of the stations' position was obtained using gLAB, an open-source PPP software written in C [30]. Motivation for using the package was determining whether it would be possible to obtain a similar quality with commercial top-level class software like Bernese [31]. One important aspect of PPP processing is that each software execution is independent. Spreading such processing into several threads or even computers is straightforward, enabling the creation of a scalable and disturbed system. For such processing, one execution uses a single core in the CPU. When launching another calculation, another core was occupied, enabling the total processing time to be almost twice as fast.

Selection of stations used for similar analyses varies from regional [3, 10, 21] to globally distributed sets of stations [14]. Often, different observation lengths are analysed from, among other lengths, 0.5 hour [14] to 6 days [3]. To produce 
statistically relevant results, the processing was done for 50 exemplary consecutive days between 01.01 .2012 and 19.02.2012, combining the above with different durations of 24, 12, 8, 6, 4, 3, 2 and 1 hour results in 1250, 2500, 3750, $5000,7500,10000,15000$ and 30000 calculations respectively for each period. To process such a large amount of data, a script for generating batch-execution files was created.

Finally, the solution was compared with the reference coordinates. Outliers, detected using Chauvenet's Criterion [32], were removed with other dubious results.

The final IGS satellite-precise ephemeris and clocks with intervals of 15 minutes and 30 seconds respectively were used in addition to IGS08 antenna phase center corrections. Processing was based on an L3 phase combination, and so ambiguity remained float. All possible models that could be applied in the software were used.

\section{The results}

\subsection{Convergence}

Convergence-time analyses for thresholds of 10,5,2 and $1 \mathrm{~cm}$ were done by Soycan [14]. The convergence claimed by Leandro [15] is $5 \mathrm{~cm}$ with over 2-hour period of observation and a little longer for the height component to approach the same error level. In other analyses performed by the author, horizontal coordinates reach a $5 \mathrm{~cm}$-convergence in 3 hours. It takes one hour more for 3D position error to achieve the same. The convergence time for a single station throughout a whole year by Leandro et al. [9] had similar results.

In this study, the convergence times for accuracy between 1 and $10 \mathrm{~cm}$ are estimated for 3 components based on 24-hour observations. The mean convergence times and their standard deviation and maximal times are presented in Figure 2. Within 1-hour accuracy of 3, 7 and $7 \mathrm{~cm}$ respectively for North, East and Up components (N, E and U respectively) can be expected. For these respective components, $5 \mathrm{~cm}$ is reached in 30, 90 and 120 minutes. Increasing the threshold to $10 \mathrm{~cm}$ results in convergence times below 30 minutes.
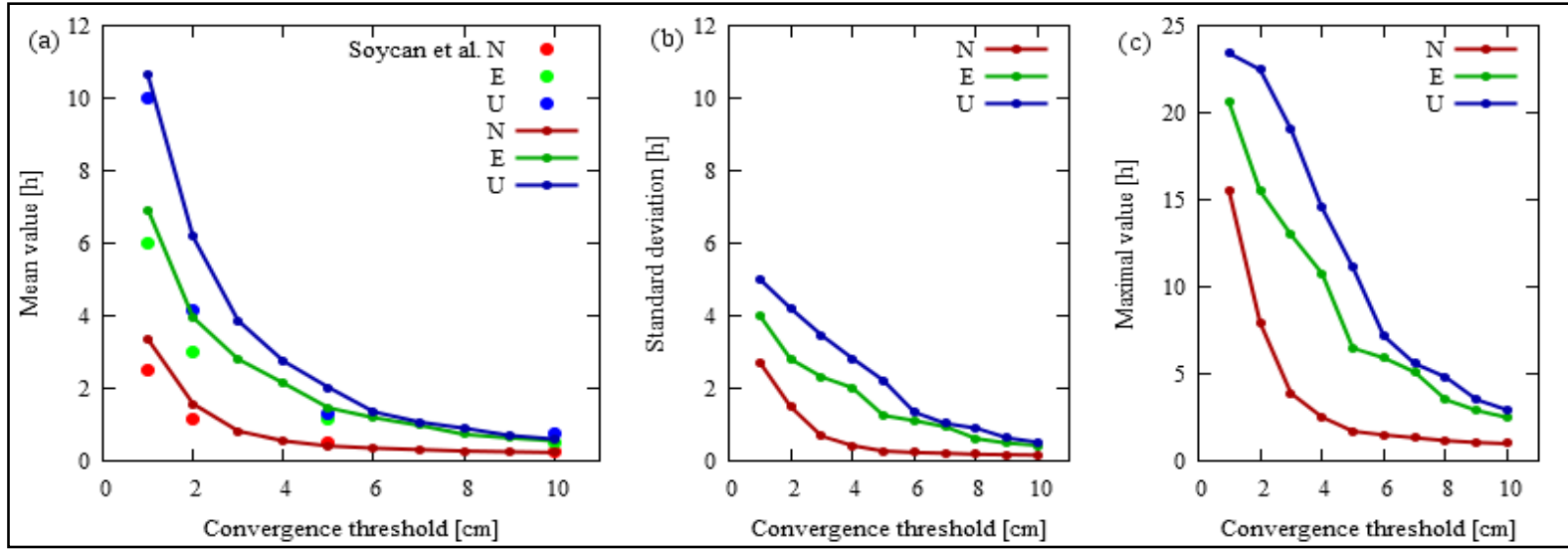

Fig. 2. Convergence time for mean values (a), standard deviations (b) and maximal times (c) in function of threshold accuracy for analysis based on 24 hour calculations

The exponential nature of mean values is observed. The variability of convergence times is influenced by satellite geometry and station-specific conditions (i.e. multipath, variation of conditions). High day-to-day variability in convergence times is observed even for single stations [12].

\subsection{The accuracy}

Assuming that the accuracy of PPP results depends on the length of observation, the analyses were preformed for several lengths. Calculation results are presented in Figure 3 and in Table 1. An exponential relation is observed between the mean, standard deviation, extreme values, and observation length. The results show that accuracy and precision of the software used is comparable albeit slightly worse than more sophisticated commercial software. The mean value for horizontal components can be assumed to be constant and does not exceed $2 \mathrm{~mm}$ for all observation periods. The mean value for height component is less stable. It exceeds $2 \mathrm{~mm}$ for observation periods shorter than 6 hours and increases up to over $1.5 \mathrm{~cm}$ for 1-hour observation periods.

Significant mean value deviations, higher than $5 \mathrm{~mm}$, are observed for observation periods shorter than 3 hours, reaching $17 \mathrm{~mm}$ for 1-hour observations. Adding models not covered by the software should reduce the convergence period and remove the deviation of the mean from zero. This is not observed when using Bernese where such significant deviations by the height component from the mean appear for 0.5-hour observations [14]. Further comparisons could be performed on this 
issue, which could reveal the influence of applied models of troposphere and effects like ocean tide or atmospheric pressure loading and others - all of which are not handled in the calculations.

For approximating the length accuracy the Eqn (3) can be applied [16, 33], where $k$ is a constant coefficient estimated based on results and $T$ is observation length in hours. Based on the analysed data, $k$ rates of 2.1, 3.9 and $5.5 \mathrm{~cm} \sqrt{h}$ fit N, E and $U$ components respectively.

$$
S=k / \sqrt{T}
$$

Table 1. Mean value $(\mu)$ and standard deviation $(\sigma)$ for observation lengths from 24 to 1 hours

\begin{tabular}{lllllll}
\hline $\mathrm{T}(\mathrm{h})$ & & \multicolumn{2}{c}{} & \multicolumn{2}{c}{$\boldsymbol{\sigma}$} \\
& $\mathrm{N}(\mathrm{mm})$ & $\mathrm{E}(\mathrm{mm})$ & $\mathrm{U}(\mathrm{mm})$ & $\mathrm{N}(\mathrm{mm})$ & $\mathrm{E}(\mathrm{mm})$ & $\mathrm{U}(\mathrm{mm})$ \\
\hline 24 & 1 & 1 & 1 & 5 & 7 & 12 \\
12 & 1 & 1 & 0 & 6 & 9 & 15 \\
8 & 1 & 1 & 0 & 7 & 11 & 19 \\
6 & 1 & 0 & 1 & 7 & 12 & 22 \\
4 & 1 & 0 & 3 & 9 & 18 & 26 \\
3 & 1 & -1 & 5 & 11 & 23 & 31 \\
2 & 1 & 1 & 9 & 14 & 34 & 40 \\
1 & 2 & 2 & 17 & 23 & 64 & 61 \\
\hline
\end{tabular}

Further analysis could focus on correlating the extreme values with conditions and station quality that may have some influence on positioning. The extreme values for errors reach several centimeters for most cases; for observation periods shorter than 4 hours for height component it reaches $10 \mathrm{~cm}$.

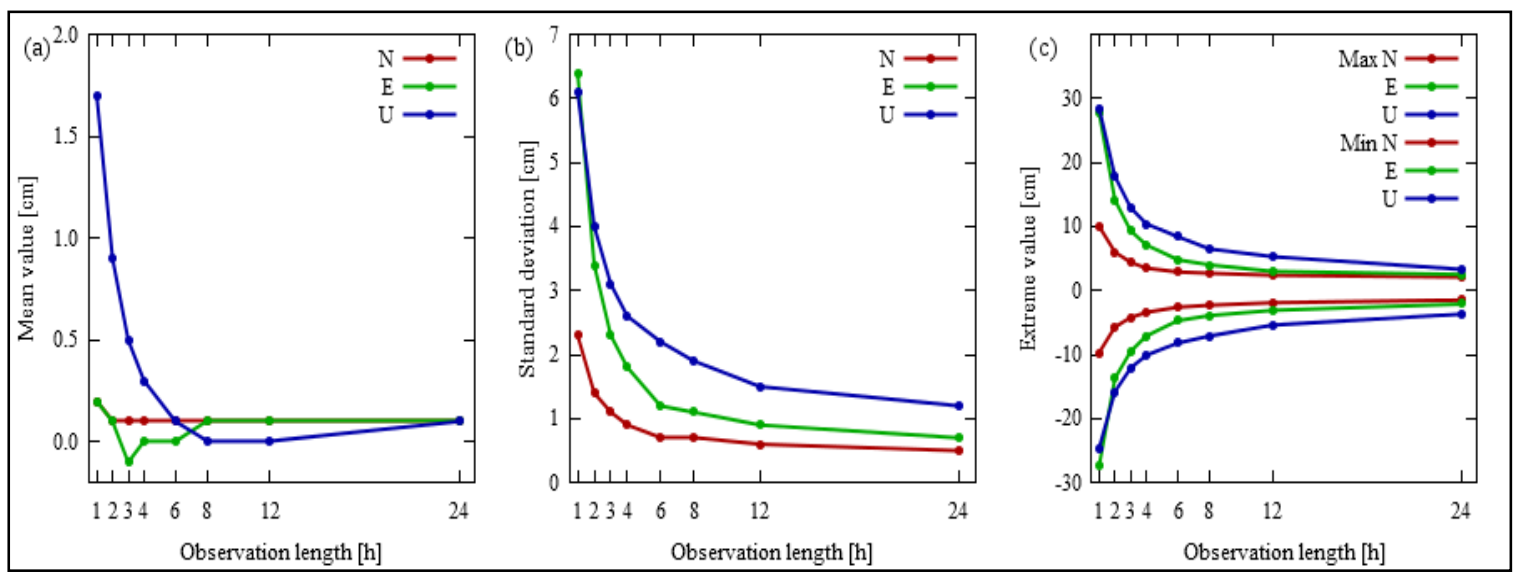

Fig. 3. Mean value (a), standard deviation (b) and extreme values (c) for different observation lengths T.

\section{PPP Applications}

When using the PPP method, all effects modeled during processing can be estimated [34]. Among them, there are atmospheric dynamics, tidal effects. Station clock corrections are also estimated in PPP and so they can be applied to the time transfer. However, the further part of the paper will focus on applications utilizing position as a result of the PPP method.

Conventional GPS-based positioning is commonly used in monitoring earthquakes, seismic wave propagation, volcanic eruptions, magmatic intrusions, movements of ice, landslides, structure and dynamics of the atmosphere, and space weather [35].

PPP became an alternative for the relative method based on double differencing of phase observations. The main factor when choosing between the two methods is the distance from the closest reference station. At the moment, PPP suits areas where no reference station networks are established $[13,16]$. However, establishing and maintaining networks of reference stations are connected with infrastructure and software costs. Thus, the future potential of PPP also covers developing countries. 
PPP does not require a reference station directly, so the costs of pre-planning, logistics and personal are lower [cf. 3 , 10, 17, 28].

For long observation periods processed post-factum, the accuracy of PPP is comparable to the conventional method; however, field measurements often require shorter times. In this case, it is worth establishing a second station even when no reference station is present in the vicinity of the measured area. The second station, computed with PPP, could be used as a reference station. The PPP technique is also more suitable for non-experienced scientists from disciplines other than Geodesy, because many PPP post-processing software packages are free and available online. In addition, they are less complicated than commercial ones [e.g. 17, 30].

Applications based on PPP are not limited to area, as coverage is global. The precise ephemeris used by the method globally provides a homogenous and consistent reference system.

The method can be used to establish a geodetic survey control network [3]. Processes connected with movements of only several centimeters or decimeters per year, like crustal deformations and landslides, can be effectively monitored using the technique in static post-processed mode [cf. 16, 36]. Sub-centimeter annual crustal deformations due to hydrological loading can also be observed using the technique [37].

Real-time natural hazards and early warning monitoring systems can benefit from fixing integer-ambiguities in PPP [24]. Taking observation from a sparse IGS station in order to obtain satellite clock corrections can bring real-time PPP solution to $5 \mathrm{~cm}$ and $10 \mathrm{~cm}$ horizontally and vertically, respectively [17]. Based on a local reference station network, centimeterlevel positioning can be reached within tens of minutes [24].

\section{Summary}

A few-centimeter level accuracy may be expected for measurement lengths longer than 4 hours for the performed analysis. The quality is obtained by simple and free open source desktop software.

PPP as an absolute method for positioning can be of much benefit in its application in geosciences. The costs of preplanning, logistics and personal are lower when comparing it to differential solution. Satellites are the direct homogenous and consistent reference system for PPP with the quality of the solution depending on the satellite geometry (in addition to station specific environment). This opposes constraint of distribution of reference station network in relative technique. This enables application of it in areas where no reference stations are established. In areas covered with reference stations PPP may be applied for its usage simplicity (online services). The accuracy and convergence constraint may determine the actual service that will be used. Real-time measurements enable decimeter-level accuracy with long convergence time of several hours with may be decreased significantly by applying sparse network of reference station and fixing the ambiguities. The method is actively researched and significant improvements, especially in convergence time, may be expected in near future.

The parameters included in the PPP model may be directly estimated. In addition, the quality of positioning may be used in many geosciences applications.

\section{References}

[1] Zumberge, J. F.; Heflin, M. B.; Jefferson, D. C.; Watkins, M. M.; Webb, F. H. 1997. Precise Point Processing for the Efficient and Robust Analysis of GPS Data from Large Networks, Journal of Geophysical Research: Solid Earth 102(B3): 5005-5017. http://dx.doi.org/10.1029/96JB03860

[2] Gao, Y. 2006. Precise Point Positioning and Its Challenges, InsideGNSS 1(8): 16-18.

[3] Ebner, R.; Featherstone, W. E. 2008. How well can online GPS PPP post-processing services be used to establish geodetic survey control networks?, Journal of Applied Geodesy 2(3): 149-157. http://dx.doi.org/10.1515/JAG.2008.017

[4] Kouba, J. 2009. A guide to using International GNSS Service (IGS) products [cited 20 December 2013]. Available from Internet: $\mathrm{ftp}$ //ww.igs.org/igscb/resource/pubs/UsingIGSProductsVer21.pdf.

[5] Griffiths, J.; Ray, J. R. 2009. On the precision and accuracy of IGS orbits, Journal of Geodesy 83(3-4): 277-287. http://dx.doi.org/10.1007/s00190008-0237-6

[6] Héroux, P.; Kouba, J. 2001. GPS precise point positioning using IGS orbit products, Physics and Chemistry of the Earth, Part A: Solid Earth and Geodesy 26(6-8): 573-578. http://dx.doi.org/10.1016/S1464-1895(01)00103-X

[7] Hofmann-Wellenhof, B.; Lichtenegger, H.; Wasle, E. 2008. GNSS - Global Navigation Satellite Systems. Wien: Springer-Verlag. 516p.

[8] Grinter, T.; Roberts, C. 2011. Precise Point Positioning: Where are we now?, in Proc. of the IGNSS Symposium (IGNSS2011), Sydney, Australia, 2011.

[9] Leandro, R. F.; Santos, M. C.; Langley R. B. 2011. Analyzing GNSS data in precise point positioning software, GPS Solutions 11(1): 1-13. http://dx.doi.org/10.1007/s10291-010-0173-9

[10] Stępniak, K.; Wielgosz, P.; Paziewski, J. 2012. Badania dokładności pozycjonowania techniką PPP w zależności od długości sesji obserwacyjnej oraz wykorzystanych systemów pozycjonowania satelitarnego [Analysis of PPP accuracy depending on observing session duration and GNSS systems used], Biuletyn WAT [Military University of Technology Bulletin] 61(1): 429-450.

[11] Abdel-salam, M. 2005. Precise Point Positioning Using Un-Differenced Code and Carrier Phase Observations. PhD Thesis, University of Calgary, $206 \mathrm{p}$.

[12] Bisnath, S.; Gao, Y. 2009. Current State of Precise Point Positioning and Future Prospects and Limitations, in M. G. Sideris. Observing our Changing Earth. International Association of Geodesy Symposia 133, 2009. Berlin: Springer-Verlag, 615-623.

[13] Landau, H.; Chen, X.; Klose, S.; Leandro, R.; Vollath, U. 2009. Trimble's RTK and DGPS Solutions in Comparison with Precise Point Positioning, in M. G. Sideris (Ed.). Observing our Changing Earth. International Association of Geodesy Symposia 133, 2009. Berlin: Springer-Verlag, 709-718. 
[14] Soycan, M. 2012. A Quality Evaluation of Precise Point Positioning within the Bernese GPS Software Version 5.0, Arabian Journal for Science and Engineering 37(1): 147-162. http://dx.doi.org/10.1007/s13369-011-0162-5

[15] Leandro, R. F.; Santos, M. C. 2006. Wide Area Based Precise Point Positioning, in Proc. of the ION GNSS-06, Fort Worth, USA.

[16]Wang, G. Q. 2013. Millimeter-accuracy GPS landslide monitoring using Precise Point Positioning with Single Receiver Phase Ambiguity (PPP-SRPA) resolution: a case study in Puerto Rico, Journal of Geodetic Science 3(1): 22-31. http://dx.doi.org/10.2478/jogs-2013-0001

[17] Zhang, X.; Li, X.; Guo, F.; Li, P.; Wang, L. 2010. Server-based real-time Precise Point Positioning and its application, Chinese Journal of Geophysics 53(3): 372-379. http://dx.doi.org/10.1002/cjg2.1506

[18] Cai, C. and Gao, Y. 2007. Precise Point Positioning Using Combined GPS and GLONASS Observations, Journal of Global Positioning Systems, 6(1): 13-22. http://dx.doi.org/10.5081/jgps.6.1.13

[19] Azab, M.; El-Rabbany, A.; Shoukry, M. N; Khalil, R. 2011. Precise Point Positioning Using Combined GPS/GLONASS Measurements, in Proc. of the FIG Working Week 2011, Marrakech, Morocco 2011.

[20] Alcay, S.; Inal, C.; Yigit, C. O. 2012. Contribution of GLONASS Observations on Precise Point Positioning, in Proc. of the FIG Working Week 2012, Rome, Italy 2012.

[21] Krzan, G.; Dawidowicz, K.; Świątek, K. 2013. Analysis of current position determination accuracy in Natural Resources Canada Precise Point Positioning Service, Artificial Satellites 48(3): 111-124. http://dx.doi.org/10.2478/arsa-2013-0010

[22] Ge, M.; Gendt, G.; Rothacher, M.; Shi, C.; Liu, J. 2008. Resolution of GPS carrier-phase ambiguities in Precise Point Positioning (PPP) with daily observations, Journal of Geodesy 82(7): 389-399. http://dx.doi.org/10.1007/s00190-007-0187-4

[23] Geng, J.; Meng, X.; Dodson, A. H.; Teferle, F. N. 2010. Integer ambiguity resolution in precise point positioning: method comparison, Journal of Geodesy 84(9): 569-581. http://dx.doi.org/10.1007/s00190-010-0399-x

[24] Geng, J.; Teferle, F. N.; Meng, X.; Dodson, A. H. 2011. Towards PPP-RTK: Ambiguity resolution in real-time precise point positioning, Advances in Space Research 27(10): 1664-1673. http://dx.doi.org/10.1016/j.asr.2010.03.030

[25] Chen, K.; Gao, Y. 2005. Real-Time Precise Point Positioning Using Single Frequency Data, in Proceedings of the 18th International Technical Meeting of the Satellite Division of The Institute of Navigation (ION GNSS 2005), Long Beach, CA, 2005, $1514-1523$.

[26] Choy, S. L. 2009. An investigation into the accuracy of single frequency precise point positioning, PhD Thesis, RMIT University, 244p.

[27] van der Marel, H.; de Bakker, P. F. 2012. Single versus Dual-Frequency Precise Point Positioning, InsideGNSS 7(4): 30-35.

[28] Rizos, C.; Janssen, V.; Roberts, C.; Grinter, T. 2012. Precise Point Positioning: Is the Era of Differential GNSS Positioning Drawing to an End?, in Proc. of the FIG Working Week 2012, Rome, Italy 2012

[29] Rebischung, P.; Griffiths, J.; Ray, J.; Schmid, R.; Collilieux, X.; Garayt, B. 2012. IGS08: the IGS realization of ITRF2008, GPS Solutions 16(4): 483494. http://dx.doi.org/10.1007/s10291-011-0248-2

[30] Hernandez-Pajares, M.; Juan, J. M.; Sanz, J.; Ramos-Bosch, P.; Rovira-Garcia, A.; Salazar, D.; Ventura-Traveset, J.; Lopez-Echazarreta, C.; Hein, G. 2010. The ESA/UPC GNSS-Lab tool (gLAB): an advanced multipurpose package to process and analyse GNSS data, in 5th ESA Workshop on Satellite Navigation User, Noordwijk, The Netherlands, 2010.

[31] Dach, R.; Hugentobler, U.; Fridez, P.; Meindl, M. 2007. User Manual of Bernese GPS Software Version 5.0, Astronomical Institute, University of Bern.

[32] Taylor, J. R. 1996. An Introduction to Error Analysis: The Study of Uncertainties in Physical Measurements. Sausalito: University Science Books. $327 \mathrm{p}$.

[33] Eckl, M. C.; Snay, R. A.; Soler, T.; Cline, M. W.; Mader, G. L. 2001. Accuracy of GPS-derived relative positions as a function of interstation distance and observing-session duration, Journal of Geodesy 75(12): 633-640. http://dx.doi.org/10.1007/s001900100204

[34] Petit, G.; Luzum, B. 2010. IERS Conventions. Frankfurt am Main: Verlag des Bundesamts fur Kartographie und Geodasie, 2010. 179 p.

[35] Hammond, W. C.; Brooks, B. A.; Bürgmann, R.; Heaton, T.; Jackson, M.; Lowry, A. R.; Anandakrishnan, S. 2011. Scientific Value of Real-Time Global Positioning System Data, Eos, Transactions American Geophysical Union 92(15): 125-126. http://dx.doi.org/10.1029/2011EO150001

[36] King, M.; Aoki, S. 2003. Tidal observations on floating ice using a single GPS receiver, Geophysical Research Letters 30(3): 1138. http://dx.doi.org/10.1029/2002GL016182

[37] Rajner, M.; Liwosz, T. 2011. Studies of crustal deformation due to hydrological loading on GPS height estimates, Geodesy and Cartography 60(2): 135-144. http://dx.doi.org/10.2478/v10277-012-0012-y 